\title{
Evaluating Teachers of International Business Education in NUAA Based on Efficacy Using AHP
}

\author{
Monpattra Thiranun \\ College of Economics and Management \\ Nanjing University of Aeronautics and Astronautics, China \\ Haiyan Xu \\ College of Economics and Management \\ Nanjing University of Aeronautics and Astronautics, China
}

\begin{abstract}
Efficacy evaluation has just become famous in the last decade. This paper aims to show one case study, Efficacy Evaluation of International Business Teacher in NUAA, which being evaluated by students. In the step of design criteria for teacher efficacy evaluation in this case, using concept of four factors model by Brouwers and Tomic (2003) and Student Evaluation Teaching (SET) to design criteria, sub-criteria, and indicators. This paper wanted to show teacher efficacy evaluation by evaluating effectiveness of teacher and setting a goal to achieve. All data in this paper are from asking International Business students to fill the survey. After collecting data, it showed that 76 students in International Business major think that their teachers are efficacious enough in the term of teacher's personality and given workload, but other criteria should still have some improvements. Finally, the result from this paper can help improving the performance of International Business teachers in NUAA but it does not mean that the improvement is necessary.
\end{abstract}

Keyword: efficacy, evaluation, teacher, student, SET, effectiveness, criteria, survey

\section{INTRODUCTION}

In the last decade, the term efficacy becomes more well-known in many studies, especially in medical study and educational study. And for educational study, it can be focused in different aspects such as; school efficacy, university efficacy, student efficacy, and teacher efficacy. Teacher efficacy is an important concept. Guskey (2000) came up that the evaluation can guide the reformation of school with better information and also professional development efforts. Woolfolk and Spero (2005) said that teacher efficacy is one of the few reasons that related to students' achievement. Nanjing University of Aeronautics and Astronautics (NUAA) was established in October 1952. NUAA started accepting international students largely since 2005; College of International Education was established since then. Aeronautical engineering was the first full time major for international undergraduate students. After that, another three majors was started too, including International Business, Mechanical Engineering and Software Engineering. In this article, we focused on International Business major. International Business major was established in 2007. Currently there are over 470 undergraduate international students from around 40 countries over the world.

Efficacy is the ability to produce an expected quantity of the expected quality, or success in achieving a given goal. It deals with achieving goals by using criteria in the action of solving problem. So, teacher efficacy is a self-perception of competence rather than a measure of actual competence. In this case, almost all teachers in International Business class in NUAA are 
Chinese who have to teach foreign students from all over the world in English. There are cultural and languages differences to consider.

Brouwers and Tomic (2003) found that a four-factor model for teacher elf-efficacy evaluation is better fit model, compared to other models. The four-factors from Brouwers and Tomic's study are teaching efficacy (overcoming environmental factors), personal efficacy (one's teaching/instruction activities), outcome efficacy (activities to reach educational outcomes) and classroom management efficacy (activities to manage student behavior). In this paper used this four-factor model as a guideline to design criteria for teacher efficacy evaluation and also used Student Evaluation Teaching (SET). To date, there is no particular model to evaluate efficacy of International Business Teacher in NUAA yet. It is hard or impossible to design ideal and fixed criteria for every teacher efficacy evaluation case study, because it should be flexible and depends on many factors and points of view in each case but the criteria can be designed as close as to the perfect one. There are surveys for teacher efficacy before, however it is not specific for International Business teacher in NUAA. So, this article showed the methodology for this specific case.

Particularly, we addressed three aims: First, design suitable criteria for evaluation of efficacy of International Business Teacher in NUAA. Second, calculate result from questionnaire. Third, summarize the teacher achieving goals result and suggest teacher's future performance from the evaluation. All can be found in detail in the following. The structure of this paper is as follows: Section 2 describes the about efficacy and teacher efficacy evaluation model, Section 3 focuses on how to design criteria for evaluating efficacy of International Business teacher in NUAA, Section 4 explains the result of evaluation in this case, and Section 5 shows the conclusion of this paper.

\section{Efficacy}

\section{BACKGROUND OF TEACHER EFFICACY EVALUATION}

"If Efficiency is doing things right and Effectiveness is doing right things, then Efficacy is about being just right". This is the famous definition to explain Efficacy and differentiate it from Efficiency and Effectiveness. Efficacy is to set a target and accomplish it. You expect to succeed in your aim and at the end you can do it, then you are efficacious. For example, a student is setting a goal to get 90 scores or above in Math in this semester and finally this student gets 95, so this student is efficacious. No matter which way you use to achieve the goal or how much you spend on it, since you achieved the goal you are efficacious. Charles Chow (2014) explained the components of efficacy that efficacy serves an order with the right way (doing things right) in order to result in the right deliverables (doing the right things). So, Efficacy can be doing something effectively with goal.

\section{Teacher efficacy evaluation model}

Teacher evaluation can be obtained by seven sources of data according to William (1989); oneself, files, chairman/dean, peers (faculty members), colleagues, administrators, and students. He recommended that using multiple sources of data in teacher evaluation if you want accurate evaluating and improve teaching. This paper will use students as source of data. For student-rating result, it helps improving performance of teacher, but it does not mean that the improvement from student-rating result is needed. The evaluating by students may enhance the way of teaching and make students learn more effectively and efficiently [13]. Brouwers and Tomic's study tested two factors model study by Gibson and Dembo (1984) which are personal efficacy and teaching efficacy, three factors model study by Emmer and Hickman (1991) which included classroom management efficacy, and four factors model study 
by Soodak and Pedell (1996) that included outcome efficacy. They said this four factors model fitted better than other models, even though it does not perfectly fit for all. So, the four factors are teaching efficacy (overcoming environmental factors), personal efficacy (one's teaching/instruction activities), outcome efficacy (activities to reach educational outcomes) and classroom management efficacy (activities to manage student behavior).

Student Evaluation of Teaching (SET) is usually used as the basis for evaluation of teacher effectiveness. SET is the most important, and sometimes the only, measure of teaching effectiveness (d'Apollonia \& Abrami, 1997). Flinders University mentioned some aspects in teacher evaluation included

1. Quality, amount, and level of classroom instruction

2. Development of curricula, new courses, and classroom materials

3. Supervision and mentoring of graduate students, including chairing of dissertations

4. One-on-one consultation with students, including supervision of independent study and reading courses

5. Supervision of teaching assistants in undergraduate courses

6. Conduct and supervision of laboratory instruction

7. Advising students in the major

8. Supervision of field work

9. Supervision of clinical and practicum experiences.

10. Teaching competence and skills

11. Stimulation and enthusiasm

12. Rapport and fairness with students

13. Organization and preparation

14. Appropriate workload

15. Assessment.

Some idea of four factors model and Student Evaluation of Teaching (SET) will be used together in designing criteria for case study. It can be found in section 3.

\section{Analytic Hierarchy Process (AHP)}

Analytic Hierarchy Process (AHP) is a famous method in multi-criteria decision making (MCDM). The special characteristic of AHP is to convert evaluation (quality) into numerical value (quantity) and calculate its weight, so it can be used in comparison. AHP has three main level in hierarchy tree; goal, criteria, and alternatives. In some case, it may have four levels by adding sub-criteria to before alternatives level. After defining goal, criteria and alternatives, and establishing hierarchy tree, the decision makers have to evaluate each criterion and alternative by comparing two elements a time as ratio. After that, input ratio into pairwise matrices and follow by other processes.

The procedure of AHP has four steps as;

1. Generate pairwise matrices

2. Generate the weights of the measures

3. Normalize weights to get the consistency among measures

4. Calculate the overall ratings

These steps can be calculated by using YaAHP software. Here is the figure of hierarchy tree created in YaAHP software. 

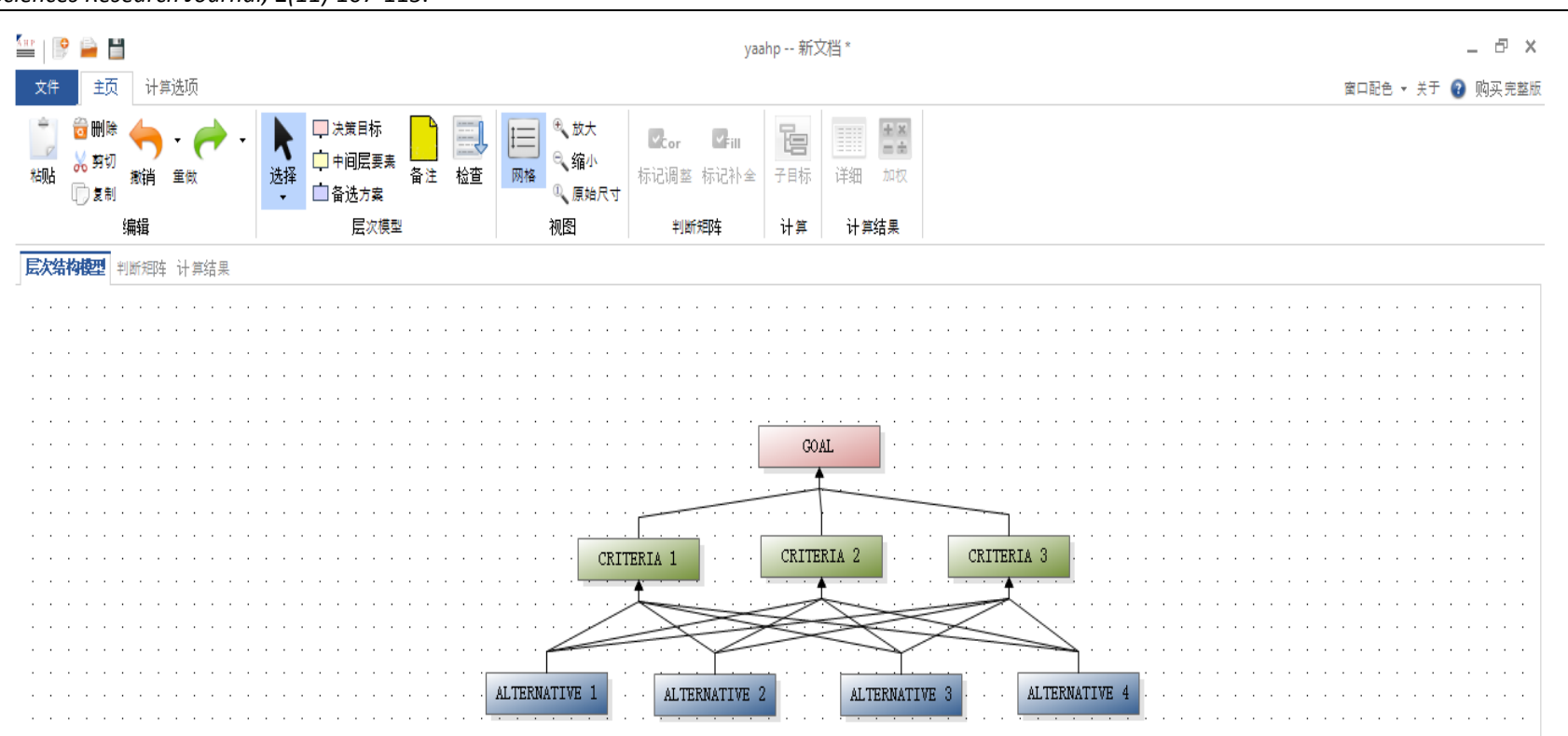

Fig. 1 Analytic Hierarchy tree

\section{Efficacy Evaluation of International Business Teacher in NUAA}

There are many studies about evaluation of teachers, but most of them focused on efficiency or effectiveness or even self-efficacy [1], [5- 9]. Current research focused on efficacy evaluation of International Business teacher in NUAA. The evaluation of teacher efficacy in this paper stipulated as the capability of teachers to achieve some goals being evaluated from students' point of view. Since the terms Effectiveness and Efficacy are somehow related, so achieving effective goals can explain the term efficacy in this case.

There is still no specific theoretical model for efficacy evaluation of International Business teacher in NUAA being evaluated by students yet. This section will show how authors design criteria and attributes for the specific case. To know how effective teachers and teaching are. They should be indicated by teachers and students, since no one else is there with them in classroom. The evaluation by other people in college will not be exactly direct point. William E. Cashin (1989) suggested some points that how do others know that those teachers are effective teachers? Do they depend on the complaints of students, gossip, or the overheard comments from somewhere? That is the reason of authors to choose International Business students as the evaluators. Teacher self-efficacy evaluation can be future work and other evaluators also.

As in Section 2.2, based on the four factors model and Student Evaluation of Teaching (SET) aspects can be modified to suit this case. Since SET is teaching evaluation and teaching is one factor from four factors model. And also, other aspects from SET match in four factors model. That idea leads authors to table 1 below. 
Table 1. Design criteria for Efficacy evaluation of International Business teachers in NUAA

\begin{tabular}{|c|c|c|c|c|c|}
\hline \multicolumn{6}{|c|}{ Teacher Efficacy evaluation's criteria } \\
\hline $\begin{array}{l}\text { Teacher's } \\
\text { Language }\end{array}$ & Teachers' skill & $\begin{array}{l}\text { Teacher's } \\
\text { personality }\end{array}$ & $\begin{array}{c}\text { Rapport and } \\
\text { Fairness with } \\
\text { students }\end{array}$ & $\begin{array}{c}\text { Teaching } \\
\text { organization and } \\
\text { preparation }\end{array}$ & Workload \\
\hline Fluency & Basic knowledge & Appearance & Harmony & Lesson plan & Workload quality \\
\hline Pronunciation & $\begin{array}{l}\text { Professional } \\
\text { Qualification }\end{array}$ & Clarity & Concern & Time & Workload quantity \\
\hline \multirow[t]{7}{*}{ Communication } & General knowledge & Maintaining & Understanding & Teaching method & Workload difficulty \\
\hline & Empathy & & Support & Materials selection & \\
\hline & Effective knowledge & & Interaction & Techniques & \\
\hline & & & Contact & Materials use & \\
\hline & & & Cooperation & Materials quality & \\
\hline & & & & $\begin{array}{l}\text { Classroom } \\
\text { management }\end{array}$ & \\
\hline & & & & Class effectiveness & \\
\hline
\end{tabular}

The table above can simply be criteria for effectiveness evaluation also but as mentioned before it has to set goal to be efficacy evaluation. In this case, we set all indicators to achieve more than or equal to $50 \%$ plus their weights as in table 2 and the weight will be calculate in section 4. Since, the weight tells that how important the criterion is according to student's opinion, it also means that students expect high score of performance from high weight of criterion. So, the authors designed goal to be $50 \%$ as standard plus weight of each criterion. 
Table 2. Framework of Efficacy evaluation of International Business teachers in NUAA

\begin{tabular}{|c|c|c|c|}
\hline \multicolumn{4}{|c|}{ Teacher Efficacy evaluation in NUAA } \\
\hline Criteria & Indicators & Goal to achieve & Achieved score \\
\hline \multicolumn{4}{|l|}{ Teacher's Language } \\
\hline Fluency & Teachers are fluent in English & $\geq 50 \%+$ weight & Calculate from survey \\
\hline Pronunciation & Teachers have adequate pronunciation. & $\geq 50 \%+$ weight & Calculate from survey \\
\hline Communication & $\begin{array}{l}\text { Students have no difficulty in communicating with Teachers, } \\
\text { it can be in English or Chinese. }\end{array}$ & $\geq 50 \%+$ weight & Calculate from survey \\
\hline \multicolumn{4}{|l|}{ Teachers's kill } \\
\hline Basic knowledge & $\begin{array}{l}\text { Teachers have basic knowledge in the field of "International } \\
\text { Business" education. }\end{array}$ & $\geq 50 \%+$ weight & Calculate from survey \\
\hline $\begin{array}{l}\text { Professional } \\
\text { Qualification }\end{array}$ & $\begin{array}{l}\text { Teachers are professional / knowledgeable in their own } \\
\text { subjects. }\end{array}$ & $\geq 50 \%+$ weight & Calculate from survey \\
\hline General knowledge & $\begin{array}{l}\text { Teachers understand economic situation between students' } \\
\text { countries and China. }\end{array}$ & $\geq 50 \%+$ weight & Calculate from survey \\
\hline Empathy & $\begin{array}{l}\text { Teachers give adequate feedback to students in their } \\
\text { progress. }\end{array}$ & $\geq 50 \%+$ weight & Calculate from survey \\
\hline Effective knowledge & $\begin{array}{l}\text { Students have clear knowledge in the field of International } \\
\text { Business major after classes. }\end{array}$ & $\geq 50 \%+$ weight & Calculate from survey \\
\hline \multicolumn{4}{|c|}{ Teacher's personality } \\
\hline Appearance & Teachers' appearances or presence styles are appropriate. & $\geq 50 \%+$ weight & Calculate from survey \\
\hline Clarity & Teachers can project well or teach with loud and clear voice. & $\geq 50 \%+$ weight & Calculate from survey \\
\hline Maintaining & Teachers can maintain attentions of students & $\geq 50 \%+$ weight & Calculate from survey \\
\hline \multicolumn{4}{|l|}{$\begin{array}{l}\text { Rapport and Fairness } \\
\text { with students }\end{array}$} \\
\hline Harmony & Teachers can establish good rapport with students. & $\geq 50 \%+$ weight & Calculate from survey \\
\hline Concern & Teachers show concern and interest to students. & $\geq 50 \%+$ weight & Calculate from survey \\
\hline Understanding & Teachers listen and understand students' concerns. & $\geq 50 \%+$ weight & Calculate from survey \\
\hline Support & $\begin{array}{l}\text { Teachers support students who have learning difficulties and } \\
\text { challenges. }\end{array}$ & $\geq 50 \%+$ weight & Calculate from survey \\
\hline Interaction & Teacher-student interaction is effective. & $\geq 50 \%+$ weight & Calculate from survey \\
\hline Contact & It is easy to meet teachers outside of class room. & $\geq 50 \%+$ weight & Calculate from survey \\
\hline Cooperation & Students are well involved and encouraged. & $\geq 50 \%+$ weight & Calculate from survey \\
\hline \multicolumn{4}{|l|}{$\begin{array}{l}\text { Teaching organization } \\
\text { and preparation }\end{array}$} \\
\hline Lesson plan & Teachers prepare proper lesson plan. & $\geq 50 \%+$ weight & Calculate from survey \\
\hline Time & Teachers can teach all required lesson on time. & $\geq 50 \%+$ weight & Calculate from survey \\
\hline Teaching method & $\begin{array}{l}\text { Teachers use suitable methods for foreign students in } \\
\text { International Business class. }\end{array}$ & $\geq 50 \%+$ weight & Calculate from survey \\
\hline Materials selection & $\begin{array}{l}\text { Teachers select appropriate materials for International } \\
\text { Business class such as; reference, ppt, and books. }\end{array}$ & $\geq 50 \%+$ weight & Calculate from survey \\
\hline Techniques & $\begin{array}{l}\text { Students satisfy with teachers' techniques of class } \\
\text { management. }\end{array}$ & $\geq 50 \%+$ weight & Calculate from survey \\
\hline Materials use & Teachers use materials and board effectively. & $\geq 50 \%+$ weight & Calculate from survey \\
\hline Materials quality & Materials are effective. & $\geq 50 \%+$ weight & Calculate from survey \\
\hline Classroom management & Classes are smoothly organized and time is used well. & $\geq 50 \%+$ weight & Calculate from survey \\
\hline Class effectiveness & Organization and management of the whole class are effective. & $\geq 50 \%+$ weight & Calculate from survey \\
\hline \multicolumn{4}{|l|}{ Workload } \\
\hline Workload quality & $\begin{array}{l}\text { Homework, presentation and paper work that teachers } \\
\text { assigned are useful for students. }\end{array}$ & $\geq 50 \%+$ weight & Calculate from survey \\
\hline Workload quantity & The amount of work is appropriate for the class. & $\geq 50 \%+$ weight & Calculate from survey \\
\hline Workload difficulty & $\begin{array}{l}\text { The level of work difficulty is appropriate for International } \\
\text { Business students. }\end{array}$ & $\geq 50 \%+$ weight & Calculate from survey \\
\hline
\end{tabular}

William (1990) said in his recommendation 4 that to have reliable students rating data, at least collecting data from ten students, if possible.. The authors managed to collect data from 76 students for this case.

\section{RESULT ANALYSIS}

After collecting 76 survey results, input the results in Microsoft Excel and sum all scores of each question after that calculate the percentage of achieved scores. Since the maximum score of each question is 5 (strongly agree) and total 76 students filled the questionnaires, so the maximum total score is $5^{*} 76=380$. Another part of questionnaire asking about comparison of criteria by considering between Teacher's language and other criteria. Here is the result using 
SPSS software for counting the numbers of students who choose each criterion, also can use Microsoft Excel. (Table 3)

Table 3. Summary of criteria comparison

\begin{tabular}{|l|r|r|}
\hline & Frequency & Percent \\
\hline $\begin{array}{l}\text { Teacher's } \\
\text { language }\end{array}$ & 31 & 40.8 \\
\hline Teacher's skill & 45 & 59.2 \\
\hline & & \\
\hline $\begin{array}{l}\text { Teacher's } \\
\text { language }\end{array}$ & Frequency & Percent \\
\hline $\begin{array}{l}\text { Teacher's } \\
\text { personality }\end{array}$ & 47 & 61.8 \\
\hline & 29 & 38.2 \\
\hline $\begin{array}{l}\text { Teacher's } \\
\text { language }\end{array}$ & Frequency & Percent \\
\hline $\begin{array}{l}\text { Rapport and } \\
\text { fairness with } \\
\text { students }\end{array}$ & 22 & 28.9 \\
\hline
\end{tabular}

\begin{tabular}{|l|r|r|}
\hline & Frequency & Percent \\
\hline $\begin{array}{l}\text { Teacher's } \\
\text { language }\end{array}$ & 28 & 36.8 \\
$\begin{array}{l}\text { Teaching } \\
\text { organization } \\
\text { and } \\
\text { preparation }\end{array}$ & 48 & 63.2 \\
\hline & Frequency & Percent \\
\hline $\begin{array}{l}\text { Teacher's } \\
\text { language }\end{array}$ & 45 & 59.2 \\
\hline workload & 31 & 40.8 \\
\hline
\end{tabular}

Then, use ratios of five pairs of criteria from Table 3 in YaAHP software (Foreology software, 2013) to calculate pairwise matrix and get the weight of each criterion. (Fig. 2)

Fig. 2 Weights of criteria

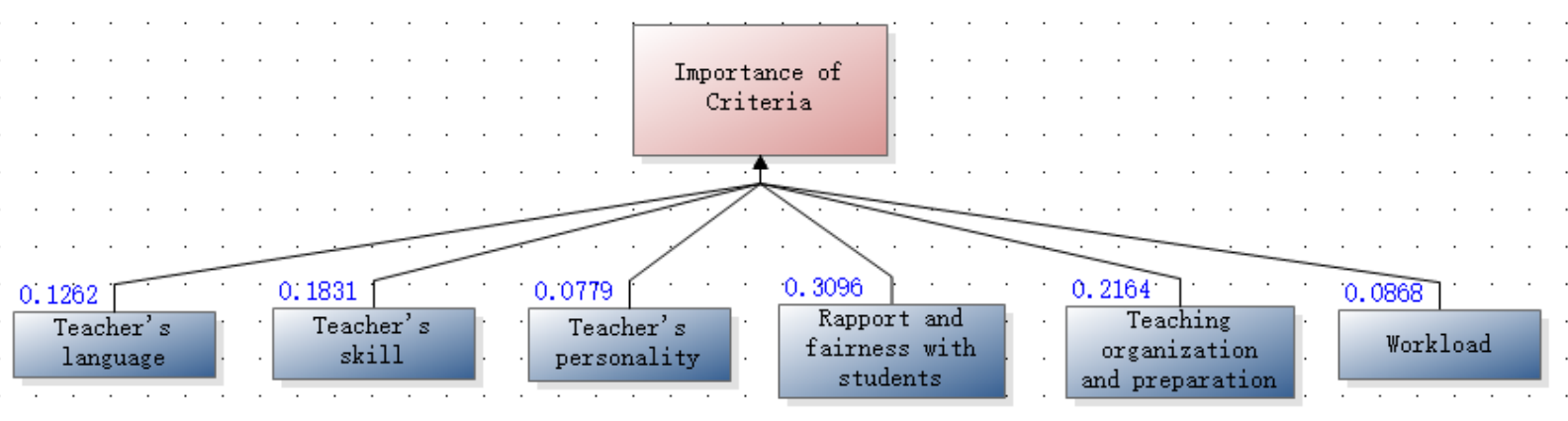

The weights of criteria from YaAHP software surprisingly showed that in students' opinion "rapport and fairness with students" is the one that they consider the most or the most important criterion among other criteria with the highest weight 0.3096 and the lowest is teacher's personality, 0.0779 .

As mentioned in Table 2, goal to achieve is more than or equal to $50 \%$ plus its weight and now we have weight of each criterion from YaAHP (Fig. 2), so it can be concluded as
1. Teacher's language
$=50 \%+12.62 \%=62.62 \%$
2. Teacher's skill
$=50 \%+18.31 \%=68.31 \%$
3. Teacher's personality
$=50 \%+7.79 \%=57.79 \%$
4. Rapport and fairness with students
$=50 \%+30.96 \%=80.96 \%$
5. Teaching organization and preparation
$=50 \%+21.64 \%=71.64 \%$
6. Workload
$=50 \%+8.68 \%=58.68 \%$ 
The result below in Table 4 showed the total scores and percentages of every indicator with its goal.

Table 4. Result of efficacy evaluation

\begin{tabular}{|c|c|c|c|c|c|c|c|c|}
\hline & Q1 & Q2 & Q3 & Q4 & Q5 & Q6 & Q7 & Q8 \\
\hline Total & 203 & 215 & 234 & 294 & 307 & 233 & 246 & 247 \\
\hline Max. score & 380 & 380 & 380 & 380 & 380 & 380 & 380 & 380 \\
\hline $\begin{array}{c}\text { Percent of } \\
\text { achieved } \\
\text { score (\%) }\end{array}$ & 53.42 & 56.58 & 61.58 & $\mathbf{7 7 . 3 7}$ & $\mathbf{8 0 . 7 9}$ & 61.32 & 64.74 & 65.00 \\
\hline Goal (\%) & & 62.62 & & & & 68.31 & & \\
\hline
\end{tabular}

\begin{tabular}{|c|c|c|c|c|c|c|c|c|c|c|}
\hline & Q9 & Q10 & Q11 & Q12 & Q13 & Q14 & Q15 & Q16 & Q17 & Q18 \\
\hline Total & 292 & 247 & 235 & 260 & 263 & 252 & 248 & 247 & 236 & 239 \\
\hline Max. score & 380 & 380 & 380 & 380 & 380 & 380 & 380 & 380 & 380 & 380 \\
\hline $\begin{array}{l}\text { Percent of } \\
\text { achieved } \\
\text { score (\%) }\end{array}$ & 76.84 & 65.00 & 61.84 & 68.42 & 69.21 & 66.32 & 65.26 & 65.00 & 62.11 & 62.89 \\
\hline Goal (\%) & & 57.79 & & & & & 80.96 & & & \\
\hline
\end{tabular}

\begin{tabular}{|c|c|c|c|c|c|c|c|c|c|c|c|c|}
\hline & Q19 & Q20 & Q21 & Q22 & Q23 & Q24 & Q25 & Q26 & Q27 & Q28 & Q29 & Q30 \\
\hline Total & 292 & 289 & 249 & 283 & 244 & 264 & 267 & 261 & 260 & 278 & 258 & 253 \\
\hline \begin{tabular}{c} 
Max. score \\
\hline $\begin{array}{l}\text { Percent of } \\
\text { achieved } \\
\text { score (\%) } \\
\text { Goal (\%) }\end{array}$
\end{tabular} & $\mathbf{7 6 . 8 4}$ & $\mathbf{7 6 . 0 5}$ & 65.53 & $\mathbf{7 4 . 4 7}$ & 64.21 & 69.47 & 70.26 & 68.68 & 68.42 & $\mathbf{7 3 . 1 6}$ & $\mathbf{6 7 . 8 9}$ & $\mathbf{6 6 . 5 8}$ \\
\hline
\end{tabular}

The result of teacher efficacy evaluation by students in Table 4. showed that teacher's language and rapport and fairness with students criteria are not achieved their goals when teacher's personality and workload fulfilled the goals. For teacher's skill and teaching organization and preparation, some indicators achieved the goals but most of them did not, so the overall of these two criteria are not succeeded.

\section{CONCLUSION AND FUTURE WORK}

This paper explained the concept of teacher efficacy evaluation and its model. There are a lot of aspects to consider in teacher evaluation. The combination of concepts of four factors model by Brouwers and Tomics, and Student Evaluation Teaching (SET) is the selection of important aspects in teacher efficacy evaluation. From the result showed that teacher's personality and workload for students criteria are fine, but the others should have some improvements according to student's opinion. Students may think that if they have more time with teachers, according to the highest weight of "Rapport and fairness with students" criteria, it may improve their study. The next study can try different sources of data or self-evaluation. In the future, we can consider efficiency and effectiveness evaluation together with efficacy as 3-EF approach. And also, evaluate the overall International Business major, not only teacher evaluation.

\section{ACKNOWLEDGEMENT}

The authors are thankful for the financial support from the National Natural Science Foundation of China (NSFC) (71471087), National Social Science Foundation of China (12AZD102), and Nanjing Government Scholarship. We also would like to thank International 
Business students in NUAA who helped us fill the questionnaires. Thank you to everyone who gave us opportunities to do this work.

\section{Reference}

1. Cristina Pérez-Espés and José María Moreno Jiménez and Maria A. Wimmer, Evaluating the Efficacy of EParticipation Experiences, EGOV/ePart Ongoing Research, 2013, Page 250-257.

2. http://en.wikipedia.org/wiki/Nanjing_University_of_Aeronautics_and_Astronautics

3. http://en.wikipedia.org/wiki/Analytic_hierarchy_process

4. Thomas L. Saaty, Decision making with the analytic hierarchy process [J], International J. Services Sciences, 2008, Vol.1, No.1

5. Donna Tangen, Thesis title: A contextual measure of teacher efficacy for teaching primary school students who have ESL, PhD thesis of faculty of education of Queensland University of Technology, 2007.

6. Bin Hua, Evaluation of the efficacy of a Chinese herbal medicine in the treatment of patients with osteoarthritis of the knee, PhD thesis of Victoria University, Australia, 2012.

7. Dana Anne Miyuki Tomonari, A Professional Development Program Evaluation:

8. Teacher Efficacy, Learning, And Transfer, PhD thesis of University Of Southern California, 2012.

9. Ceylandağ, F. Rana M.S., Teacher Self-Efficacy Beliefs Toward Measurement And Evaluation Practices, Master thesis of Middle East Technical University, September 2009, 94 pages.

10. Mark W. Lipsey and David B. Wilson, The Efficacy of Psychological, Educational, and Behavioral Treatment Confirmation from Meta-Analysis, the American Psychological Association, Inc., 1993.

11. Charles Chow, Management Efficacy Wisdom from Indian Bhagavad Gita and the Chinese Art of War, McGraw-Hill Education (Asia), ISBN 978-1-259-07108-9, 2014

12. William E. Cashin, IDEA paper no. 21: Defining and Evaluating College Teaching, Division of Continuing Education Kansas State University, 1989.

13. William E. Cashin, IDEA paper no. 22: Student Ratings of Teaching: Recommendations for use, Division of Continuing Education Kansas State University, 1990.

14. Karen A. Loveland, Student Evaluation of Teaching (SET) in Web-based Classes: Preliminary Findings and a Call for Further Research, Texas A\&M University - Corpus Christi, The Journal of Educators Online, Volume 4, Number 2, July. 